\title{
Direct dating of resin hafted point technology in Australia
}

Tim Maloney', Rachel Wood ${ }^{2}$, Sue O'Connor and Rose Whitau'

1. Department of Archaeology and Natural History, College of Asia and the Pacific, The Australian National University ACT 0200, Australia <Tim.maloney@anu.edu.au>

2. Radiocarbon Facility, Research School of Earth Sciences, College of Physical and Mathematical Science, The Australian National University ACT 0200, Australia <Rachel.wood@anu.edu.au>

3. Department of Archaeology and Natural History, College of Asia and the Pacific, The Australian National University ACT 0200, Australia <sue.oconnor@anu.edu.au>

4. Department of Archaeology and Natural History, College of Asia and the Pacific, The Australian National University ACT 0200, Australia $<$ rose.whitau@anu.edu.au>

\begin{abstract}
The rare recovery of hafting technology from archaeological deposits around the world prevents a clear picture of Palaeolithic hafting arrangements. Without the recovery of hafted stone tools, our understanding of this technology is limited to extrapolation from artefact morphology and ethnographic analogy, and such is the case in Australia. Here we present a direct date of 3160-2954 cal. BP, obtained from resin on a stone point recovered from Carpenters Gap 1 rockshelter in northern Western Australia. This artefact fits the description of point technology in Australia, being a retouched flake with converging margins, and provides the first direct date of hafting resin in situ on a stone tool from the Australian continent. The hafting arrangement of a stone point during the mid- to late Holocene is archaeologically visible for the first time in Australia. This point was hafted using resin adhesive as well as wound binding material. This rare artefact is used to discuss the current interpretations of technological change in the Holocene record of Australia and the direct dating process.
\end{abstract}

\section{Introduction}

Excavation at Carpenters Gap 1 (CG1), a site with exceptional organic preservation in the southern Kimberley, Western Australia (McConnell and O'Connor 1997, 1999; O'Connor 1995; Wallis 2001) (Figure 1), recovered a distal point fragment with a sizable portion of adhering resin with imprints of an organic binder. This paper presents the results of direct dating of the resin and a description of the imprints and stone artefact. This is the first Australian stone tool to be directly dated using adhering resin and demonstrates how this method can be used to provide reliable ages for a range of Australian composite tools, as well as assist us to understand hafting technology better.

Unifacial and bifacial points first appear in parts of Australia in the mid-Holocene (Hiscock 2008:158; Maloney et al. 2014), although the dating of the appearance of these tools (and other hafted tools) has not been without contention. Points are widely identified as retouched flakes with converging margins (Hiscock 2006:76; Holdaway and Stern 2004:266). Dating the appearance of this technology has conventionally relied on dating organics in associated excavation units. In sandy deposits, however, the assumption of association is problematic, as bioturbation and other disturbance can lead to vertical movement of objects up and down the profile (e.g. O'Connor et al. 2002; Richardson 1992). Direct dating of resin has the potential to provide reliable ages for the diversity of hafted tools that appear across Australia in the Holocene.
The impressions preserved in the resin of the CG1 point also provide evidence of the methods involved in its hafting, indicating the use of organic binders as well as mastic.

The process of hafting was a crucial technological development in human evolution. The expansion of hominid populations resulted in the adaptation of hafting technologies to a myriad environmental, social and economic conditions across the globe. A vital component of the toolkit (Shea 2006), hafted technology is still employed by some hunter-gatherer groups today (Weedman 2006). Despite the ubiquity of hafting technology, direct evidence of hafting in the archaeological record is rare, limiting our understanding of how this technology was adapted to novel conditions.

Archaeologically, there are three elements that can provide evidence of hafting: the tool itself, the haft and the binding agent. The earliest evidence for hafting technology is based on diagnostic impact fractures on tools, such as those fractures found on points excavated from the Kathu Pan 1 site in South Africa and dated by association to 500,000 years (Wilkins et al. 2012:943; see also Barham 2002). The earliest spear shafts were recovered from the Schöningen site in Germany (Thieme 1997), dated to 400,000 years, but no lithic projectiles were recovered, prompting the authors to conclude that the spears were fashioned entirely from wood. The earliest organic evidence of compound hafting matrix was identified on Middle Stone Age tools, dated to 70,000 years, from Sibudu Cave in South Africa (Wadley et al. 2009:9590). Birch tar residues have been recovered on 


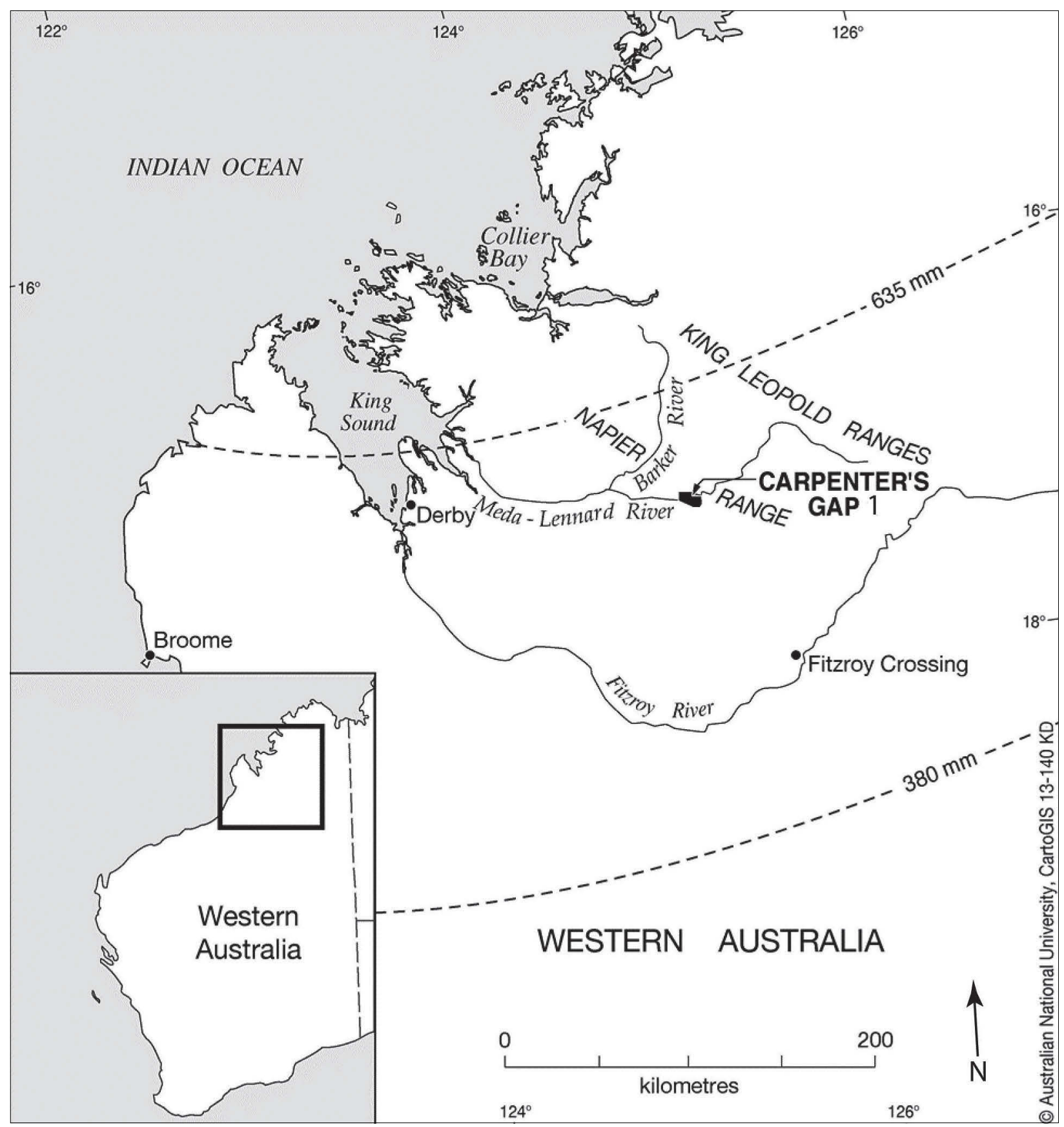

Figure 1 Map of north Western Australia showing site location.

stone tools from several European Palaeolithic sites (Boëda et al. 1996; Mazza et al. 2006; Pawlik and Thissen 2011:1707), including a birch tar piece with impressions of a stone tool, a wooden artefact and fingerprints (Grünberg 2002; Hedges et al. 1998; Koller et al. 2001).

Recovery of early hafting technology throughout Asia has been rare and few studies demonstrate composite tool use before the terminal Pleistocene. In Timor Leste, the butt end of a bone projectile from Matja Kuru 2 (MK2) has been dated to ca 32,000 cal. BP, by association with radiocarbon dates of marine shell (O'Connor et al. 2014b:110-111). This artefact preserves evidence of a complex hafting mechanism, which employed an organic fibre wrapped around a mastic on the bilaterally notched butt. At Niah Cave in Borneo several bone and stingray spine points, with traces of hafting resin and fibrous binding, have been dated to the terminal Pleistocene, based on association with charcoal radiocarbon dates (Barton et al. 2009:1708-1709). Hafting of backed artefacts using resinous mastic was practised in the late Pleistocene at Jwalapuram Locality 9, in India (Clarkson et al. 2009:334, 339), but only a few of the recovered artefacts retained resin, inhibiting a convincing interpretation of the composite arrangement (Clarkson et al. 2009:339). The only other direct evidence for early hafting comes from northern China where use-wear analysis on adzes and projectile points indicates that these artefacts were used in composite tools from around 10,000 years ago (Zhang et al. 2009).

The earliest colonisers of Sahul, who employed complex seafaring technology (Balme and O'Connor 2015), are likely to have been adept at fibre processing and resin manufacture and use. On encountering new environments these early settlers developed new hafting technology and made edge-ground and waisted axes, since whole axes and flakes detached from them have been recovered from the 
earliest levels of some of the oldest sites in northern Australia (Clarkson et al. 2015:59; Geneste et al. 2012:2; O'Connor 1999:175; O'Connor et al. 2014a:18; Schrire 1982:84, 106107). McConnell and O'Connor (1997:24-27) suggested that the abundance of resinous spinifex culms in the Pleistocene assemblage at CG1 may indicate early resin production for hafting. Prior to the CG1 point discussed here, the only direct dates obtained from manufactured resin in Australia have been reported from surface assemblages in the Pilbara, WA (Veitch et al. 2005:60, Table 1), where two spinifex balls were dated to within the last 1000 years. Despite the continuing dearth of physical evidence, hafting remains central to explanations of technological change in Australia.

The mid-Holocene has long been recognised as a period of dynamic technological and social change across the continent of Australia, with either new forms of stone tools or the proliferation of existing stone technologies becoming widespread. Most of the evidence for hafting technology has been extrapolated from tool morphology. A generally small size, pointed termination, elongation and proximal thinning of many tools have led some archaeologists to argue that hafting was a central technological requirement of these tools (e.g. Allen and Barton 1989:121; Clarkson 2007:155, 2008:302; Clarkson and David 1995:22; Flood 2004:225; Hiscock 1994:277; Mulvaney 1969:153; Mulvaney and Joyce 1965). Innovation in hafting techniques was hypothesised as an overall explanation for new stone tools across the continent during the mid-Holocene (Jones 1979:456-457; Mulvaney 1969:153). The implied hafting of points and backed artefacts was also used to argue for increased conflict (Flood 1995:236; Smith 1995:40; Smith and Brockwell 1994:102). Recent explanations of the development of points and backed artefacts tend either to support a technological response to foraging risk (Clarkson 2007:155; Hiscock 1994:277; 2011), and/or a social response to demographic changes (Moore 2013; White 2011). Hafting features prominently in both scenarios. The foraging risk model argues that points as standardised implements allowed continuous hafting and rejuvenation within the same costly, pre-designed hafting arrangement (Clarkson 2007:155, 2008:302; Hiscock 1994:278). Social signalling explanations, on the other hand, suggest that points were hafted as highly visible symbols of identity and social status (Moore 2013:145).

Points are a likely candidate for hafting as projectiles due to their shape, although it is also apparent that points were used for a range of functions both with and without other hafting arrangements. Limited resin recovery has hitherto prohibited reconstruction of hafting arrangements. For example, the only residue analysis of points thus far carried out yielded two of 42 points with possible traces of hafting resin but no dating of the resin was attempted (Wallis and O'Connor 1998:10). Additionally, while hafting is largely inferred from the morphology, the pointed shape was not always maintained (Clarkson 2007:112, 114, 117; Hiscock 2009:84-85; Maloney and O'Connor 2014). Macrofracture analysis of points from the Northern Territory reveals that mid-Holocene points may rarely have been used as hafted projectiles (Brindley and Clarkson 2015). Conversely, a few studies that showcase hafting resins on backed artefacts were able to confirm that multiple hafting arrangements were employed (Boot 1993:5, Tables 8-11; Brown 1987:49; Robertson et al. 2009:249,297) with projectile tips or barbs utilised less frequently (McDonald et al. 2007).
Without over-extending the application of ethnographic analogy (Binford 1972:86), more recent and museum curated examples of stone tool hafting can be informative. In northern Australia, ethnographic observation and collection have provided useful insights into recent forms of point hafting technology (Akerman 1978:486; Akerman et al. 2002:21-22; Hardman 1888:64-64; Kaberry 1939:14; Newman and Moore 2013). For example, Akerman (1978:486) described the ethnographic hafting of Kimberley points, which are present in archaeological deposits around 1000 cal. BP (Maloney et al. 2014). Other forms of point and blade hafting described by Newman and Moore (2013:2615, Fig. 1), Spencer and Gillen (1899:652), Graham and Thorley (1996:78-79), Bindon and Lofgren (1982:119, Fig. 6), and McCarthy et al. (1946:32), demonstrated that, in recent times, multiple hafting arrangements were used. Ethnographers such as Roth $(1897,1904)$ provided accounts of hafting a range of stone artefacts, including what would not be recognised as formal tools (see Khan 1993). There are also examples of handles created from mastic and binding, with no incorporated shaft (Newman and Moore 2013:2615, Fig. 2), and large blades hafted as knives (Akerman 2007).

\section{Sources of Resin in Australia}

Ethnographically, resins were observed being extracted from a range of plant species across Australia (Aiston 1929:45; Boot 1993:5; Latz 1995:341; Maiden 1975; Parr 1999:23; Richardson 1988:58). In the Kimberley, resin was extracted from Triodia pungens (spinifex), the roots of Erythrophleum chlorostachys (ironwood), and Callitris columellaris (native cypress pine) (Akerman pers. comm. 2014). Other sources of resin include native bee (Trigona sp.) hives (Akerman pers. comm. 2014) and ant nests (Akerman 1980:246; Latz 1995:290; Lowe and Pike 2009; Spencer 1896:69-71), probably produced by Iridomyrmex rostrinatus (Butler 1966). The use of ant nests for resin production is possibly a more recent technological development (Pitman 2010:89-91). Again, more recently, burnt battery cases and tar from sealed roads were used in hafting technologies (Akerman 1980:246). In north Queensland, the young roots of the ironwood tree Erythrophleum laboucherii were processed for resin production (Khan 1993:87). In the same area, Roth (1897) noted dry lumps of gum gathered from the brown cedar or mackay cedar tree Canarium australasicum, which were used for joining spear shafts (see Khan 1993:130).

Spinifex resin, a thermoplastic adhesive, is the most prolific source of plant resin in Australia (Pitman 2010; Pitman and Wallis 2012). The threshing of spinifex, in order to extract the resin, was practised across much of the continent where resinous spinifex occurred (Binford 1984; Brokensha 1975; Cleland 1966; De Graaf 1967; Gould 1970; Pitman 2010:3139; Roth 1904; Sheridan 1979; Tindale 1965). Spinifex grass was threshed on a hard surface and the resulting resin-chaff mixture was collected in a container (Binford 1984:161171; Gould 1970:39-40; Latz 1995:66, 290). This mixture was then winnowed, which freed scales of resin from the leaf bases. The mixture was then heated using a variety of techniques (Pitman 2010:36) and metamorphosed into a homogenous cake of resin (Cleland 1957, 1966:122, 146-147; Roth 1897:101-102, 1904:13).

Inclusions of chaff in resin are a reasonable visual indicator that the resin source was spinifex grass (Pitman 2010:102; 
Sheridan 1979:67). Other inclusions, such as sediment grains, ash, charcoal, saliva, animal fat and blood are also possible. Ochre and bird feather decorations are present on recent Kimberley points, variably covering the shaft and mastic (Akerman et al. 2002:23-24; Newman and Moore 2013:2616, Fig. 3) and have been detected on at least one mid-Holocene point (Wallis and O'Connor 1998:160, Table 2).

\section{The CG1 Hafted Point}

The hafted stone tool illustrated in Figure 2 meets the descriptive criteria for point technology based on several observations. Firstly, the distal portion of the tool can be observed projecting from the resin, with an intact feather termination and partial ventral surface, confirming that the tool is technically a broken retouched flake (Hiscock 2007:203). Secondly, retouch scars initiated unifacially from the ventral surface are present on the left distal margin, which, combined with the unretouched right margin, create converging margins. The marginal angle (approximately $63^{\circ}$ ) is within the morphological range of other retouched flakes described as points, such as those found throughout the Kimberley (Dortch 1977:166, Fig. 5; O'Connor 1999:7374, Fig. 5.13, Fig. 5.14; O'Connor et al. 2008:79-80, Fig 4.) and in Wardaman Country, NT (Clarkson 2006:102). Prior to breaking, the point was probably very similar to those recovered from the nearby Windjana Gorge Water Tank Shelter (O'Connor et al. 2008:79-80, Fig. 4) and Carpenters Gap 3 (O'Connor et al. 2014a:21, Fig. 10), being less than $4 \mathrm{~cm}$ in length and not particularly elongate. None of the retouch scars are covered by the resin, so it is possible that the tool was hafted with no retouch and later modified.

The resin adhering to the dorsal surface of the point has been impressed, resulting in several clearly visible parallel lines on the proximal left surface (Figure 2). Each impression is approximately $0.3 \mathrm{~mm}$ wide, with the deepest penetration of the resin observed closest to the proximal edge. These impressions continue diagonally across the surface of the resin, with reduced penetration towards the right distal portion. These impressions were produced by a thin, fibrous material, which further bound the tool to the haft. The binding material covered around half of the remaining resin, and presumably continued over the shaft portion. The impressions do not intersect.

There are small pieces of plant material within the resin (Figure 2), which provide reasonable evidence that the resin was produced from spinifex chaff. Additional inclusions of small black and red flecks, around $1 \mathrm{~mm}^{2}$, are possibly charcoal and ochre (Figure 2).

A negative flake scar initiated from the left medial margin propagates through the mid-section of the point and truncates the resin (Figure 2). This flake scar terminates before reaching the opposite margin (Figure 2), where resin can be seen covering part of the right margin. This small amount of resin is therefore covering a surface that predates the mid-section break and indicates that the right margin was contracting towards a probable platform surface. The implication of this observation is that the proximal portion is

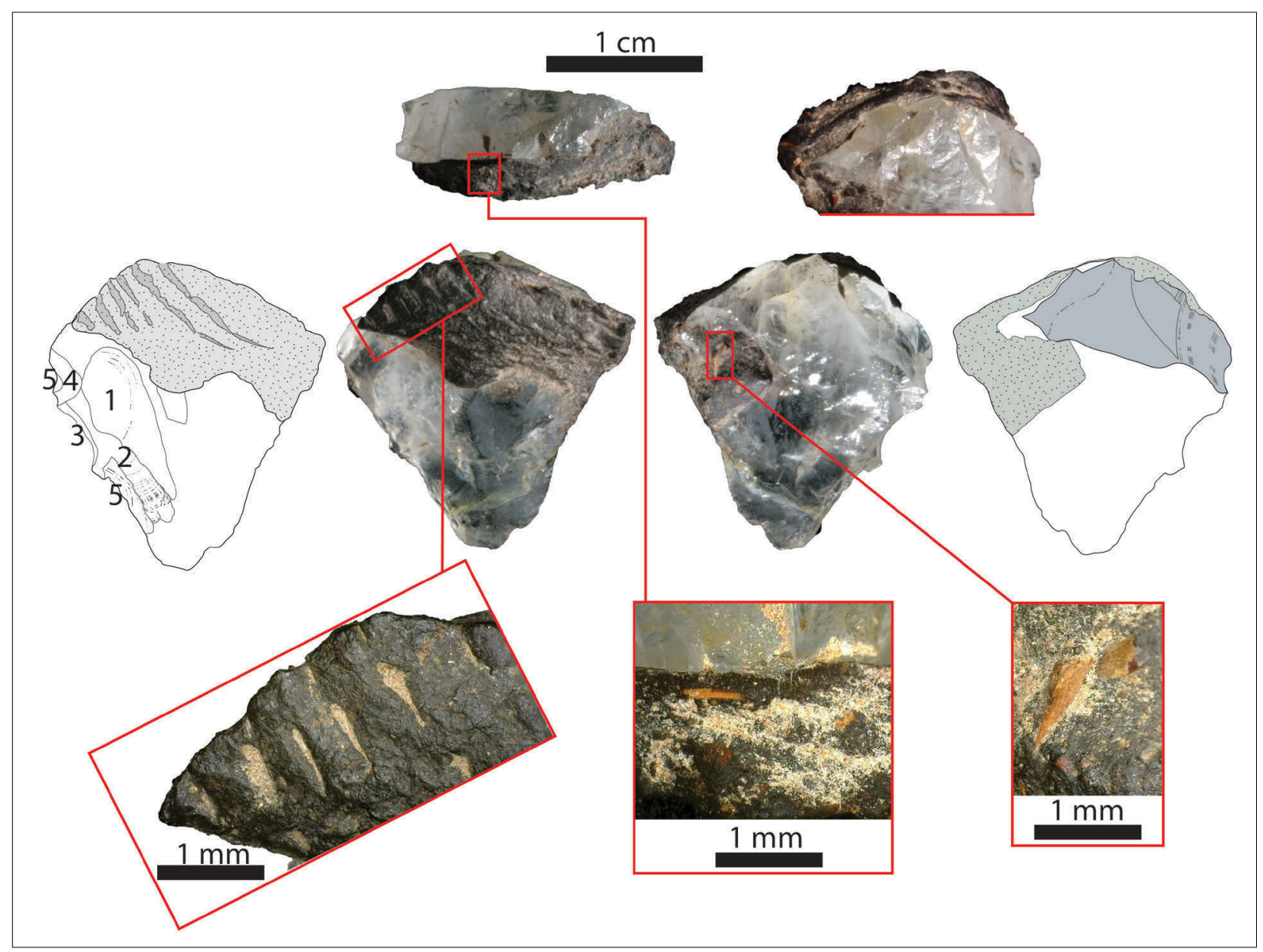

Figure 2 Point from CG1 showing transverse scar across midsection, impressions formed by binding materials and small pieces of plant, probably spinifex chaff, in the resin (photograph by Tim Maloney). 
unlikely to have been much larger than the remaining distal portion, leading to the estimated shape of the proximal portion used in Figure 3. It is possible that this scar was caused from projectile impact, given the resemblance to transverse scars observed on other hafted points (Ahler 1992:45, Fig. 11; Lombard 2005:225; Lombard et al. 2004). No other diagnostic impact fractures are evident. This fracture is perhaps less likely to have been caused during manufacture, following Ahler (1992:42, 56, Fig. 8), who demonstrated that transverse snaps observed on manufacturing failures will typically intersect or truncate retouch scars. This is not the case on the CG1 point. It is also possible that this break occurred while the tool was hafted for a non-projectile function, such as a cutting tool or drill. Given the nature of the material, crystal quartz, it is equally plausible that an incipient fracture plain propagated this transverse fracture.

The observed resin did not encapsulate the pointed distal tip. This distal portion of the tool was the only observed part to have been modified. Therefore, we can be certain that the point was hafted to utilise the acutely angled tip with converging margins, and potentially facilitated drilling, cutting and projectile functions. This assumption, in conjunction with the binding impressions and the midsection break, was used to produce the hypothetical hafting arrangement illustrated in Figure 3. Figure 3 also shows how the binding agent may have increased resistance across the mid-section of the point, initiating the break (following Fauvelle et al. 2012:2807, Fig. 5).

\section{Dating}

The excavation units (EU) surrounding the point were formed between 3632 and 2850 cal. BP, based on multiple radiocarbon dates from charcoal (Table 1). Charcoal was dated at the ANU lab in the 1990s (laboratory code ANU) and the resin directly dated more recently (laboratory code SANU). All dates have been calibrated in OxCal version 4.2 (Bronk Ramsey 2009), using the SHCal13 curve (Hogg et al. 2013), with ranges given at $95.4 \%$ probability.

The CG1 point was recovered in Unit 8c, a layer rich in organic matter including paper bark and other plant materials, and was removed separately from the surrounding sedimentary units. This unit produced a date of 3632-3365 cal. BP (ANU10030). The EU immediately above this, EU 8, dates to 3441-3076 cal. BP (ANU-10029). A hearth feature (EU 8b) truncating EU 8 dates to 3209-2927 cal. BP (ANU-11421). It is possible that the point comes from the interface of Units $8 \mathrm{~b}$ and $8 \mathrm{c}$. EU 9, which produced a date of 3557-3165 cal. BP (ANU-11460), is adjacent to, or immediately underlying, 8c. EU 10 produced a date of 3463-3164 cal. BP (ANU-11462).

The resin sample produced a calibrated age range of 31602954 cal. BP (SANU-39030) (Table 1). A $5.4 \mathrm{mg}$ piece of resin, free from visible inclusions, was taken from the right ventral margin with a scalpel. This sample was subjected to a very gentle acid-base-acid pre-treatment to remove likely contaminants: $\mathrm{HCl}(0.1 \mathrm{M}, 30$ minutes, room temperature

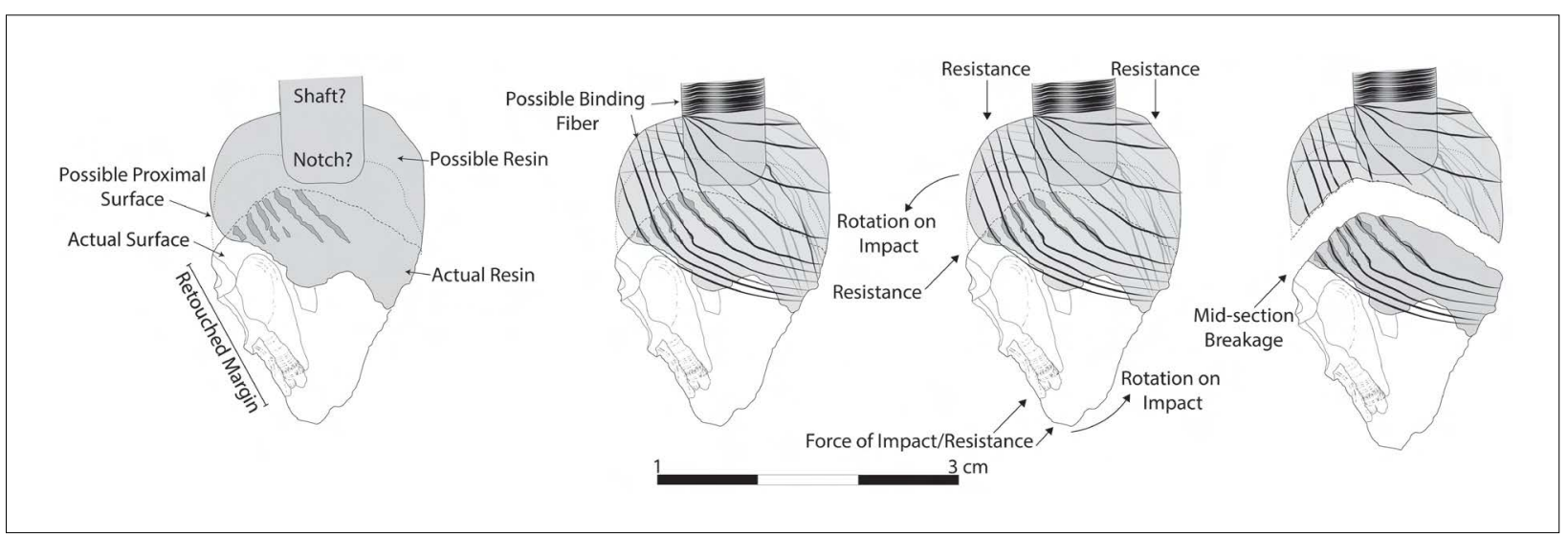

Figure 3 Hypothetical hafting arrangement and impact forces, based on specimen observations.

\begin{tabular}{|c|c|c|c|c|c|c|}
\hline Lab No. & EU & Material & Methods & $\begin{array}{c}\delta^{13} \mathrm{C}(\%) \\
\text { VPDB) }\end{array}$ & $\begin{array}{l}\text { Radiocarbon } \\
\text { date (BP) }\end{array}$ & $\begin{array}{l}\text { Calibrated age (cal BP, } \\
95.4 \% \text { probability range) }\end{array}$ \\
\hline ANU-11421 & $8 b$ & Charcoal & Conventional & - & $2960 \pm 40$ & $\begin{array}{r}3209-3191(1.7 \%) \\
3185-2927(93.7 \%)\end{array}$ \\
\hline ANU-10029 & 8 & Charcoal & $\begin{array}{r}\text { Acid wash, } \\
\text { Conventional }\end{array}$ & $-24.0 \pm 2.0^{2}$ & $3110 \pm 60$ & $\begin{array}{r}3441-3431(0.7 \%) \\
3402-3076(94.7 \%) \\
\end{array}$ \\
\hline SANU - 39039 & $8 c$ & Resin on point & $\begin{array}{r}\text { Acid-Base-Acid, AMS } \\
\text { (see text) }\end{array}$ & $-18 \pm 2.0^{1}$ & $2950 \pm 25$ & $3160-2954$ \\
\hline ANU-10030 & $8 c$ & Charcoal & $\begin{array}{r}\text { Acid wash, } \\
\text { Conventional }\end{array}$ & $-24.0 \pm 2.0^{2}$ & $3300 \pm 60$ & $3632-3365$ \\
\hline ANU-11460 & 9 & Charcoal & $\begin{array}{r}\text { Acid-Base-Acid, } \\
\text { Conventional }\end{array}$ & $-24.0 \pm 2.0$ & $3180 \pm 70$ & $\begin{array}{r}3557-3531(1.9 \%) \\
3510-3165(93.5 \%)\end{array}$ \\
\hline ANU-11462 & 10 & Charcoal & $\begin{array}{r}\text { Acid-Base-Acid, } \\
\text { Conventional }\end{array}$ & $-25.6 \pm 0.1$ & $3160 \pm 60$ & $3463-3164$ \\
\hline
\end{tabular}

Table 1 Radiocarbon dates from CG1, Square A1. Calibrated in OxCal v.4.2 (Ramsey et al. 2009) against SHCal 13 (Hogg et al. 2013 ). 
[RT]), $\mathrm{NaOH}$ (0.1 M, 45 minutes, RT), HCl (0.1 M, 30 minutes, $\mathrm{RT})$, with three washes in ultrapure $\mathrm{Milli}^{\mathrm{TM}}$ water between each treatment. The base wash appeared to dissolve the resin, but also caused the dark resin to turn a pale cream colour, and highlighted an unidentified black fleck, possibly some form of charred material. The treatment decreased the sample weight to $1.32 \mathrm{mg}$ ( $24 \%$ yield). The freeze-dried product, excluding the black fleck, was combusted in an evacuated quartz tube in the presence of silver foil and $\mathrm{CuO}$ wire at $900^{\circ} \mathrm{C}$ for 6 hours. The $\mathrm{CO}_{2}$ was then collected and purified cryogenically before reduction to graphite with $\mathrm{H}_{2}$ over an iron catalyst for measurement in a NEC Single Stage AMS (Fallon et al. 2010). The sample contained only $16 \%$ C, calculated volumetrically during cryogenic collection. The graphite weight was correspondingly low $(0.21 \mathrm{~g})$, but is within the range of sample weights routinely dated at the ANU.

Resins are rarely radiocarbon dated, and the ability of this specific pretreatment method to remove contamination added in the burial environment from a sample is not conclusively established. However, resins often give ages in agreement with other materials. For example, a radiocarbon date on resin of pine origin from a late $4^{\text {th }}$ century Roman shipwreck agreed with the date of a coin embedded in the resin (Beck et al. 1994). Resin on a microlith from Border Cave (South Africa) (OxA-X-2418-47, 35,750 $\pm 500 \mathrm{BP}$ ) gave an age in accordance with others from the same context on other materials without any pretreatment (D'Errico et al. 2012). In contrast to this Pleistocene example, large amounts ( $>1 \%$ ) of contamination are required to shift the Holocene-aged date from CG1 outside of its reported error.

A second problem may relate to the inbuilt age of the resin. As spinifex resin can be collected from ant nests, it could have an inbuilt age either from inclusion of old material, such as old wood charcoal bought into the nest, or from the use of resin from old ant mounds. On its own, the date should be treated as a maximum age for the hafting event. However, given the broad agreement between the dated resin and charcoal from surrounding contexts, it is unlikely to substantially overestimate the age of the hafting event.

\section{Discussion}

The CG1 point is the first directly dated hafted stone tool from the Australian archaeological record, providing the most conclusive evidence for mid-Holocene point hafting methods to date. The direct dating showcases the potential to date small samples of resin found on stone tools $(5.4 \mathrm{mg}$ ) effectively, which in turn will provide better understanding of the chronology of hafting technology.

The hafting arrangement of the CG1 point can be reconstructed from fibre impressions preserved in the resin and analysis of the mid-section break. The impressions indicate that the hafting of this point incorporated some form of binding over the top of the mastic, unlike ethnographic examples (Akerman 1978:486; Tindale 1985:16, Fig. 1.10), where fibres were either wound onto the shaft before the application of mastic, or avoided entirely. Measurements of the impressions show that the fibre was probably fine strands of sinew or plant, less than $0.3 \mathrm{~mm}$ in diameter, that were wound around the resin. The resin itself was probably a spinifex product, given the observation of probable chaff, implying other technological actions, including spinifex threshing, and metamorphosis into resin through heating.
The CG1 point's mid-section break was probably initiated by resistance created by the fibrous haft at the mid-section and was possibly produced by a projectile impact. It is also possible that applied pressure to the distal end was caused in any number of other functions, such as cutting or drilling, and produced a similar breakage. We would like to stress, firstly, that, while the CG1 point is an evocative example of projectile technology, it could very probably have had other functions throughout its use life, and, secondly, this hafting arrangement should not be used as a standard for the hafting of all mid to late Holocene points.

What this hafting arrangement can reveal within current explanatory models of point technology is limited, although worthy of some discussion. Points first appear in the Kimberley by at least 5200 cal. BP (Maloney et al. 2014). Rejuvenation of broken points is more likely to occur when access to replacement materials is scarce (Andrefsky 2010; Hiscock 1988), such as forays away from the CG1 site into areas where suitable point producing material was less available. Andrefsky (2010:18) noted that the archaeological recovery of points with impact damage suggests people could afford to discard the point fragment and replace it with a new point. The discard of the CG1 point could therefore relate to relatively low pressures on point rejuvenation at the time. Alternatively, its discard in proximity to locally available crystal quartz sources could simply indicate that raw material availability made rejuvenation of small points unnecessary.

Because the CG1 point is small in size, was only lightly modified and discarded without rejuvenation, it seems unlikely that this artefact attained high symbolic value and information exchange potential (Moore 2013:145). The small size of this point makes recognition of retouch only possible by close examination, which suggests that retouch was unlikely to be a requirement of social signalling via point technologies. Rather, retouch of pointed forms, with undoubted potential as social signals, was more likely focused on working edge and tip maintenance.

\section{Conclusion}

The life history of points in Australia during the mid-Holocene is beginning to be understood better with reduction-based analyses and experimental use-wear. The central role of hafting in the explanatory models of technological change surrounding point technology in the Australian record can only be expounded by the recovery of rare artefacts such as the CG1 point reported here. The dating and analysis of the mastic on the CG1 point demonstrates the huge potential of this method for elucidating the timing and nature of this technology throughout the world. Complexities of dating residues on stone tools involve the ability to remove contamination added in the burial environment, but more particularly the unknown inbuilt age. For these reasons, the direct date of resin should be treated as a maximum age for the hafting event.

\section{Acknowledgements}

The authors would like to thank the Bunuba people who worked on the excavation of the CG1 site. The direct dating of the resin was funded by the Australian Research Council (Linkage Grant LP100200415). Kim Akerman and Heidi Pitman provided useful insight into spinifex resin production. 


\section{References}

Ahler, S. 1992 Use-phase classification and manufacturing technology in Plains village arrow points. In L.J. Hofman and J.G. Enloe (eds), Piecing Together the Past: Applications of Refitting Studies in Archaeology, pp.36-62. British Archaeological Reports International Series 578. Oxford: Archaeopress.

Aiston, G. 1929 Method of mounting stone tools on Koondi: tribes east and north-east of Lake Eyre. Papers and Proceedings of the Royal Society of Tasmania 1929, pp.44-46.

Akerman, K. 1978 Notes on the Kimberley stone-tipped spear focusing on the point hafting mechanism. Mankind 11:486-489.

Akerman, K. 1980 Material culture and trade in the Kimberleys today. In C.H. Berndt and R.M. Berndt (eds), Aborigines of the West: Their Past and Their Present, pp.243-251. Crawley: University of Western Australia Press.

Akerman, K. 2007 To make a point: ethnographic reality and the ethnographic and experimental replication of Australian macroblades known as leilira. Australian Archaeology $64: 23-34$.

Akerman, K., R. Fullagar and A.V. Gijn 2002 Weapons and wunan: production, function and exchange of Kimberley points. Australian Aboriginal Studies 2002(1):13-42.

Allen, H. and G. Barton 1989 Ngarradj Warde Djobkeng: White Cockatoo Dreaming and the Prehistory of Kakadu. Sydney: University of Sydney

Andrefsky Jr, W. 2010 Human land-use strategies and projectile point damage, resharpening and discard patterns. Human Evolution 25:13-30.

Balme, J. and S. O'Connor 2015 Early modern humans in Island Southeast Asia and Sahul: adaptive and creative societies with simple lithic industries. In R. Dennell and M. Porr (eds), East of Africa: Southern Asia, Australia and Human Origins, pp.164-174. Cambridge University Press, Cambridge.

Barham, L. 2002 Backed tools in Middle Pleistocene central Africa and their evolutionary significance. Journal of Human Evolution 43:585-603.

Barton, H., P.J. Piper, R. Rabett and I. Reeds 2009 Composite hunting technologies from the terminal Pleistocene and early Holocene, Niah Cave, Borneo. Journal of Archaeological Science 36:1708-1714

Beck, C.W., D.R. Stewart and E.C. Stout 1994 Analysis of naval stores from the late Roman ship. In A.M. McCann and J. Freed (eds), Deep Water Archaeology: A Late Roman Ship from Carthage and an Ancient Trade Route near Skerki Bank off Northwest Sicily, pp.109-121. Journal of Roman Archaeology, Supplementary Series 13.

Binford, R.L. 1972 An Archaeological Perspective. Seminar Press: New York.

Binford, R.L. 1984 An Alyawara day: flour, spinifex gum and shifting perspectives. Journal of Anthropological Research 40:157-182.

Bindon, P. and M. Lofgren 1982 Walled rockshelters and a cached spear in the Pilbara region, Western Australia. Record of the West Australian Museum 10(2):111-126.

Boëda, E., J. Connan, D. Dessort, S. Muhesen, Mercler, N.S. Valladas and N. Tisnerat 1996 Bitumen as a hafting material on Middle Paleolithic artefacts. Nature 380:336-338.

Boot, P.G. 1993 Analysis of resins and other plant residues on stone artefacts from Graman, New South Wales. In B.L. Fankhauser and J.R. Bird (eds), Archaeometry: Current Australasian Research, pp.3-12. Canberra: Department of Prehistory, Research School of Pacific Studies, The Australian National University.

Brindley, J. and C. Clarkson 2015 Beyond a suggestive morphology: were Wardaman stone points exclusively spear armatures? Australian Archaeology 81:12-23.

Bronk Ramsey, C. 2009 Bayesian analysis of radiocarbon dates. Radiocarbon 51(1):337-360.
Brokensha, P. 1975 The Pitjantjatjara and Their Crafts. Sydney: The Aboriginal Arts Board, Australia Council.

Brown, S. 1987 Towards a Prehistory of the Hamersley Plateau, Northwest Australia. Occasional Papers in Prehistory 6. Department of Prehistory, Research School of Pacific Studies, The Australian National University, Canberra.

Butler, H. 1966 Obtaining spinifex gum. West Australian Naturalist 10(2):45-46.

Clarkson, C. 2006 Explaining point variability in the eastern Victoria River region, Northern Territory. Archaeology in Oceania 41:97-106.

Clarkson, C. 2007 Lithics in the Land of the Lightning Brothers: The Archaeology of Wardaman Country, Northern Territory. Terra Australis 25. Canberra: Department of Archaeology and Natural History and Centre for Archaeological Research, The Australian National University.

Clarkson, C. 2008 Changing reduction intensity, settlement and subsistence in Wardaman Country, northern Australia. In W. Andrefsky Jr (ed.), Lithic Technology: Measures of Production, Use and Curation, pp.286-316. New York: Cambridge University Press.

Clarkson, C. and B. David 1995 The antiquity of blades and points revisited: investigating the emergence of systematic blade production southwest of Arnhem Land, northern Australia. The Artefact 18:22-44.

Clarkson, C., M. Petraglia, R. Korisettar, M. Haslam, N. Boivin, A. Crowther, P. Ditchfield, D. Fuller, P. Miracle, C. Harris, K. Connell, H. James and J. Koshy 2009 The oldest and longest enduring microlithic sequence in India: 35,000 years of modern human occupation and change at the Jwalapuram Locality 9 rockshelter. Antiquity 83:326-348.

Clarkson, C., M. Smith, B. Marwick, R. Fullagar, L.A. Wallis, P. Faulkner, T. Manne, E. Hayes, R.G. Roberts, Z. Jacobs, X. Carah, K.M. Lowe, J. Mathews and S.A. Florin 2015 The archaeology, chronology and stratigraphy of Madjedbebe (Malakunanja II): a site in northern Australia with early occupation. Journal of Human Evolution 83:46-64.

Cleland, J.B. 1957 Australia: Ethnoecology_our natives and the vegetation of southern Australia. Mankind 5(4):149-162.

Cleland, J.B. 1966 The ecology of the Aboriginal in south and Central Australia. In B.C. Cotton (ed.), Aboriginal Man in South and Central Australia, pp.111-158. Adelaide: Government Printer.

D’Errico, F., L. Backwell, P. Villaa, I. Deganog, J.J. Lucejkog, M.K. Bamford, T.F.G. Higham, M.P. Colombinig and P.B. Beaumont 2012 Early evidence of San material culture represented by organic artifacts from Border Cave, South Africa. PNAS 109 (33):13214-13219

De Graaf, M. 1967 The manufacture of spinifex gum by desert Aborigines. Western Australian Naturalist 10(5):117-119.

Dortch, C.E. 1977 Early and late industrial phases in Western Australia. In R.V.S. Wright (ed.), Stone Tools as Cultural Markers: Change, Evolution and Complexity, pp.104-132. Prehistory and Material Culture Series 12. Canberra: Australian Institute of Aboriginal Studies.

Fallon, S.J., L.K. Fifield and J.M. Chappell 2010 The next chapter in radiocarbon dating at The Australian National University: status report on the single stage AMS. Nuclear Instruments and Methods in Physics Research B 268:898-901.

Fauvelle, M., E.M. Smith, S.H. Brown and M.R. Des Lauriers 2012 Asphaltum hafting and projectile point durability: an experimental comparison of three hafting methods. Journal of Archaeological Science 39:2802-2809.

Flood, J. 1995 Archaeology of the Dreamtime: The Story of Prehistoric Australia and its People. Collins: Sydney.

Flood, J. 2004 Archaeology of the Dreamtime: The Story of Prehistoric Australia and its People. Marleston: J.B. Publishing.

Geneste, J.M., B. David, H. Plisson, C. Clarkson, J.J. Delannoy and F. Petchey 2012 The origins of ground-edge axes: new findings 
from Nawarla Gabarnmang, Arnhem Land (Australia) and global implications for the evolution of fully modern humans. Cambridge Archaeological Journal 22(1):1-17.

Gould, R.A. 1970 Spears and spear-throwers of the Western Desert Aborigines of Australia. American Museum Novitates 2403:1-41.

Graham, R. and P. Thorley 1996 Central Australian Aboriginal stone knives: their cultural significance, manufacture and trade. In S.R. Morton and D.J. Mulvaney (eds), Exploring Central Australia: Society, the Environment and the 1894 Horn Expedition, pp.74-89. Chipping Norton: Surrey Beatty \& Sons.

Grünberg, M. 2002 Middle Palaeolithic birch-bark pitch. Antiquity $76: 15-16$.

Hardman, E.T. 1888 Notes on a collection of native weapons and implements from tropical Western Australia (Kimberley District). Proceedings of the Royal Irish Academy 1(1):5769.

Hedges, R.E.M., P.B. Pettit and C. Bronk Ramsey 1998 Radiocarbon dates from the Oxford AMS system: Archaeometry date list 25. Archaeometry 40:227-239.

Hiscock, P. 1988 Prehistoric Settlement Patterns and Artefact Patterns at Lawn Hill, Northwest Queensland. Unpublished PhD thesis, Department of Anthropology and Sociology, School of Social Science, University of Queensland, St Lucia.

Hiscock, P. 1994 Technological responses to risk in Holocene Australia. Journal of World Prehistory 8(3):267-292.

Hiscock, P. 2006 Blunt and to the point: changing technological strategies in Holocene Australia. In I. Lilley (ed.), Archaeology in Oceania: Australia and the Pacific Islands, pp.69-95. Oxford: Blackwell Publishing.

Hiscock, P. 2007 Looking the other way: a materialist/technological approach to classifying tools and implements, cores and retouched flakes. In S.P. McPherron (ed.), Tools Versus Cores: Alternative Approaches to Stone Tool Analysis, pp.198-222. Newcastle: Cambridge Scholars Publishing.

Hiscock, P. 2008 Archaeology of Ancient Australia. New York: Routledge.

Hiscock, P. 2009 Reduction, recycling and raw material procurement in Western Arnhem Land, Australia. In B. Adams and B. Blades (eds), Lithic Materials and Paleolithic Societies, pp.78-93. Oxford: Blackwell.

Hogg, A.G., Q. Hua, P.G. Blackwell, M. Niu, C.E. Buck, T.P. Guilderson, T.J. Heaton, J.G. Palmer, P.J. Reimer, R.W. Reimer, C.S.M. Turney and S.R.H. Zimmerman 2013 SHCal13 Southern Hemisphere Calibration, 0-50,000 years cal. BP. Radiocarbon $55(4): 1-15$.

Holdaway, S. and N. Stern 2004 A Record in Stone: the Study of Australia's Flaked Stone Artefacts. Canberra: Australian Aboriginal Studies Press.

Jones, R. 1979 The fifth continent: problems concerning the human colonisation of Australia. Annual Review of Anthropology 8:445-466.

Kaberry, P. 1939 Aboriginal Women: Sacred and Profane. London: Routledge.

Khan, K. 1993 Catalogue of the Roth Collection of Aboriginal artefacts from north Queensland. Volume 1. Items collected from Archer River, Atherton, Bathurst Head, Bloomfield River and Butcher's Hill, 1897-1901. Technical Reports of the Australian Museum 10:1-205.

Koller, J., U. Baumer and D. Mania 2001 High-tech in the middle Palaeolithic: Neanderthal-manufactured pitch identified. European Journal of Archaeology 4(3):385-397.

Latz, P.K. 1995 Bushfires and Bushtucker: Aboriginal Plant Use in Central Australia. Alice Springs: IAD Press.

Lombard, M. 2005 Evidence of hunting and hafting during the Middle Stone Age at Sibudu Cave, KwaZulu-Natal, South Africa: a multi-analytical approach. Journal of Human Evolution 48:279-300.
Lombard, M., I. Parsons and M.M. van der Ryst 2004 Middle Stone Age lithic point experimentation for macrofracture and residue analysis: the process and preliminary results with reference to Sibudu Cave points. South African Journal of Science 100:159-166.

Lowe, P. and J. Pike 2009 You Call it Desert_We Used to Live There. Broome: Margabala.

Maiden, J.H. 1975 [1889] The Useful Native Plants of Australia. Melbourne: Compendium.

Maloney, T. and S. O'Connor 2014 Backed points in the Kimberley: revisiting the north-south division for backed artefact production in Australia. Australian Archaeology 79:146-155.

Maloney, T., S. O'Connor and J. Balme 2014 New dates for point technology in the Kimberley. Archaeology in Oceania 49:137-147.

Mazza, P.P.A., F. Martini, B. Sala, M. Magi, M.P. Colombini, G. Giachi, F. Landucci, C. Lemorini, F. Modugno and E. Ribechini 2006 A new Palaeolithic discovery: tar-hafted stone tools in a European mid-Pleistocene bone-bearing bed. Journal of Archaeological Science 33:1310-1318.

McCarthy, F.D., E. Bramell and H.V.V. Noone 1946 The Stone Implements of Australia. Memoir 9. Sydney: The Australian Museum.

McConnell, K. and S. O'Connor 1997 40,000 year record of food plants in the southern Kimberley ranges, Western Australia. Australian Archaeology 44:20-31.

McConnell, K. and S. O'Connor 1999 Carpenters Gap Shelter 1: a case for total recovery. In M.J. Mountain and D. Bowdery (eds), Taphonomy: The Analysis of Processes from Phytoliths to Megafauna, pp.23-34. Research Papers in Archaeology and Natural History 30. Canberra: ANH Publications.

McDonald, J., J.D. Donlon, J.H. Field, R.L.K. Fullagar, J.B. Coltrain, P. Mitchell and M. Rawson 2007 The first archaeological evidence for death by spearing in Australia. Antiquity 81:877-885.

Moore, M.W. 2013 Simple stone flaking in Australasia: patterns and implications. Quaternary International 285:140-149.

Mulvaney, D.J. 1969 The Prehistory of Australia. London: Thames and Hudson.

Mulvaney, D.J. and E.B. Joyce 1965 Archaeological and geomorphological investigations on Mt Moffatt Station, Queensland. Proceedings of the Royal Prehistoric Society 31:147-212.

Newman, K. and M. Moore 2013 Ballistically anomalous stone projectile points in Australia. Journal of Archaeological Science 40:2614-2620.

O'Connor, S. 1995 Carpenters Gap Rockshelter 1: 40,000 years of Aboriginal occupation in the Napier Range, Kimberley, WA. Australian Archaeology 40:58-59.

O'Connor, S. 1999 30,000 Years of Aboriginal Occupation: Kimberley, North West Australia. Terra Australis 14. Canberra: Department of Archaeology and Natural History and Centre for Archaeological Research, The Australian National University.

O'Connor, S., K. Aplin and S. Collins 2008 A small salvage excavation in Windjana Gorge, Kimberley, Western Australia. Archaeology in Oceania 43:75-81.

O'Connor, S., T. Maloney, D. Vannieuwenhuyse, J. Balme and R. Wood 2014a Occupation at Carpenters Gap 3, Windjana Gorge, Kimberley, Western Australia. Australian Archaeology 78:10-23.

O'Connor, S., G. Robertson and K.P. Aplin 2014b Are osseous artefacts a window on perishable material culture? Implications of an unusually complex bone tool from the late Pleistocene of East Timor. Journal of Human Evolution 67:108-119.

O'Connor, S., M. Spriggs and P. Veth 2002 Direct dating of shell beads from Lene Hara Cave, East Timor. Australian Archaeology 55:18-21. 
Parr, J. 1999 Once, twice maybe, but not three times: reheating Xanthorrhoea australis resin. Australian Archaeology 49:23-27.

Pawlik, A.F. and J.P. Thissen 2011 Hafted armatures and multicomponent tool designs at the Micoquian site of IndenAlfdorf, Germany. Journal of Archaeological Science 38:1699-1708.

Pitman, H.T. 2010 Pointless Spinifex? An Investigation of Indigenous Use of Spinifex throughout Australia. Unpublished BArch(Hons) thesis, Department of Archaeology, Flinders University, Adelaide.

Pitman, H.T. and L.A. Wallis 2012 The point of spinifex: Aboriginal uses of spinifex grasses in Australia. Ethnobotany Research and Applications 10:109-131.

Richardson, N. 1988 Selected filmography on Aboriginal woodworking. In J. Kamminga (ed.), Wood Artefacts: a Checklist of Plant Species Utilised by Australian Aborigines, pp.26-59. Australian Aboriginal Studies 2.

Richardson, N. 1992 Conjoin sets and stratigraphic integrity in a sandstone shelter: Kenniff Cave (Queensland, Australia). Antiquity 66:408-418.

Robertson, G., V. Attenbrow and P. Hiscock 2009 Multiple uses for Australian backed artefacts. Antiquity 83:296-308.

Roth, W.E. 1897 Ethnological Studies among the North-West Central Queensland Aborigines. Brisbane: Government Printer.

Roth, W.E. 1904 Domestic Implements, Arts and Manufactures. North Queensland Ethnography Bulletin 7. Brisbane: The Home Secretary's Department, Department of Public Lands.

Schrire, C. 1982 The Alligator Rivers: Prehistory and Ecology in Western Arnhem Land. Terra Australis 7. Canberra: Department of Archaeology and Natural History and Centre for Archaeological Research, The Australian National University.

Shea, J.J. 2006 The origins of lithic projectile technology: evidence from Africa, the Levant and Europe. Journal of Archaeological Science 33(6):823-846.

Sheridan, G. 1979 Tulas and Triodia: a Multidisciplinary Investigation of the Mechanics and Antecedents of the Koondi Tuhla and their Implications for Prehistory. Unpublished MA thesis, Department of Prehistory and Anthropology, School of General Studies, The Australian National University, Canberra.

Smith, M.A. 1995 Radiocarbon dates for bifacial points at Scotch Creek 1, Northern Territory. Australian Archaeology 41:40-41.

Smith, M.A. and S. Brockwell 1994 Archaeological investigations at a stratified open site near Humpty Doo, northern Australia. In M. Sullivan, S. Brockwell and A. Webb (eds), Archaeology in the North: Proceedings of the 1993 Australian
Archaeological Association Conference, pp.84-104. Darwin: North Australia Research Unit, The Australian National University.

Spencer, W.B. 1896 Narrative, Part 1. In B. Spencer (ed.), Report on the Work of the Horn Scientific Expedition to Central Australia, pp.1-136. Melbourne: Melville, Mullen and Slade.

Spencer, W.B. and F.J. Gillen 1899 The Native Tribes of Central Australia. London: Macmillan.

Thieme, H. 1997 Lower Palaeolithic hunting spears from Germany. Nature 385:807-810.

Tindale, N.B. 1965 Stone implement making among the Nakako, Ngadadjara and Pitjandjara of the Western Desert. Records of the South Australian Museum 15:131-164.

Tindale, N.B. 1985 Australian Aboriginal techniques of pressureflaking stone implements: some personal observations. In M.G. Plew, J.C. Woods and M.G. Pavesic (eds), Stone Tool Analysis: essays in Honour of Don E. Crabtree, pp.1-33. Albuquerque: University of New Mexico Press.

Veitch, B., F. Hook and E. Bradshaw 2005 A note on radiocarbon dates from the Paraburdoo, Mount Brockman and Yandicoogina areas of the Hamersley Plateau, Pilbara, Western Australia. Australian Archaeology 60:58-61.

Wadley, L., T. Hodgskiss and M. Grant 2009 Implications for complex cognition from the hafting of tools with compound adhesives in the Middle Stone Age, South Africa. Proceedings of the National Academy of Sciences 106 (24):9590-9594.

Wallis, L. A. 2001 Environmental history of northwest Australia based on phytolith analysis at Carpenters Gap 1. Quaternary International 83-85:103-117.

Wallis, L. A. and S. O'Connor 1998 Residues on a sample of stone points from the west Kimberley. In R. Fullagar (ed.), A Closer Look: Recent Australian Studies of Stone Tools, pp.150-178. Archaeological Methods Series 6. Sydney: University of Sydney.

Weedman, K.J. 2006 An ethnoarchaeological study of hafting and stone tool diversity among the Gamo of Ethiopia. Journal of Archaeological Method and Theory 13(3):189-238.

White, J.P. 2011 Backed artefacts: useful socially and operationally. Australian Archaeology 72:67-75.

Wilkins, J., B.J. Schoville, K.S. Brown and M. Chazan 2012 Evidence for early hafted hunting technology. Science 338:942-946.

Zhang, X.L., C. Shen, X. Gao, F.U. Chen and C.X. Wang 2009 Usewear evidence confirms the earliest hafted chipped-stone adzes of Upper Palaeolithic in northern China. Chinese Science Bulletin <doi: 10.1007/s11434-009-0566-8>. 